\title{
Entre racializações: Oliver C. Cox e a sociologia
}

\author{
Erik Wellington Barbosa Borda (https://orcid.org/0000-0001-8624-5903)' \\ Programa de Pós-Graduação em Sociologia, \\ Universidade Estadual de Campinas (Unicamp), Campinas, SP, Brasil.
}

\author{
I. Erik Wellington \\ Barbosa Borda \\ é doutorando \\ do Programa de \\ Pós-Graduação \\ em Sociologia \\ da Universidade \\ Estadual de \\ Campinas, onde \\ pesquisa as \\ atividades do Centro \\ de Estudos Culturais \\ Contemporâneos \\ da Universidade de \\ Birmingham (CCCS) \\ - entre 1964 e 1982 \\ Campinas, SP, Brasil. \\ <ewbborda@gmail. \\ com>.
}

\section{Between racializations: Oliver C. Cox and the sociology}

Abstract: Oliver Cromwell Cox was a black Trinidadian sociologist that spent most of his personal and intellectual life in the United States. In this country, the heterodox character of Oliver Cox's critiques to the sociology of his time set over his work a decades long silence. In recent times, however, the growing interest in his work has brought up discussions about its foundations. This text focuses on the author's initial trajectory, a period that dates from his birth in the Caribbean, in 1901, until the publication of his magnum opus Caste, class and race, in 1948. It is argued that this period is primarily marked by a circulation of the author through different grammars of racialization, which in turn were decisive for the deconstructionist impetus that marked his towards the social sciences. It is also argued that the emphasis on this aspect of Cox's trajectory, through a critical and systemic engagement with race, offers an important contribution to the so-called externalist studies of Afrodiasporic intellectuals in Sociology.

Keywords: Oliver Cox. Race relations. Racialization. Sociology of intellectuals. Caribbean. 
1. Deve-se destacar aqui o interesse crescente pelos trabalhos de intelectuais caribenhos francófonos, dentre os quais o principal no Brasil é Frantz Fanon. No país, a atenção recebida pelo autor não é recente (Guimarães, 2008), tal como demonstra o interesse de Florestan Fernandes na divulgação de sua obra (Borda, 2014) e a escrita de um texto de balanço sobre sua vida e obra por Renato Ortiz (2014) no final da década de 1970, e publicado posteriormente. Na última década, tal atenção tem se intensificado, destacando-se aqui os trabalhos de Deivison Faustino (2015; 2018), Joaze BernadinoCosta (2016), além de outros que se inspiraram em seus escritos. Outro intelectual que tem recebido atenção é Édouard Glissant (Pinto \& Bernardes, 2019). Embora centrais para diversas discussões contemporâneas relação entre raça, classe e gênero; descolonização do pensamento; teoria pós-colonial etc. -, a produção acerca dos autores anglófonos é menos frequente. C. L. R. James teve sua principal obra, Os jacobinos negros, de 1938, traduzida no Brasil apenas em 2000. Outros escritos do autor

\section{Introdução}

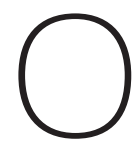
estudo acerca de intelectuais negros caribenhos ou de seu pensamento é ainda incipiente no Brasil. Apesar do interesse crescente por essa produção ${ }^{1}$, ele se limita a áreas específicas das ciências sociais voltadas ao estudo de temas sobre relações raciais em sentido amplo - estudos acerca da diáspora africana, pensamento subalterno, decolonial/pós-colonial etc. Enquanto isso, os chamados trabalhos "externalistas" acerca de intelectuais (Pontes, 1997) - redes, grupos, trajetórias -, ao mesmo tempo em que definem as diretrizes teóricas para o tratamento do tema no país, raramente incorporam aquelas discussões, ainda que possam eventualmente ter intelectuais subalternos como objeto de suas investigações. Nesse sentido, raça, além de gênero e sexualidade, "tornaram-se questão para se falar sobre, mas não foram permitidos em si a desafiar as estruturas de diálogo que facilitam o reconhecimento e geral compreensão conceituais no mundo" (Bhambra, 2007: 879)². No mesmo movimento, a tarefa de repensar as narrativas da história de nossa disciplina por esse crivo fica também limitada. Neste texto, pretendemos demonstrar, por meio de uma discussão acerca da trajetória inicial do sociólogo de Trinidad e Tobago Oliver Cromwell Cox, que o estudo de intelectuais caribenhos negros possibilita a realização de ambos os exercícios.

A discussão sobre a trajetória inicial de Oliver C. Cox, datada aqui pelo período que compreende de seu nascimento, em 1901, até a publicação de Caste, class and race, em 1948, será feita com destaque tanto aos elementos que permitiram ao autor manifestar uma posição "heterodoxa" em relação à sociologia americana de seu tempo, quanto, nesse mesmo movimento, aos elementos que determinaram sua anulação do cenário intelectual americano do pós-Guerra. Desse modo, o texto se inicia com a apresentação de um breve itinerário biográfico do autor. $\mathrm{Na}$ seção seguinte, lança-se sobre esse itinerário uma interpretação, ao mesmo tempo atenta às implicações que traz aos modelos teóricos utilizados para o estudo de intelectuais negros, particularmente caribenhos, e ao que tal itinerário pode indicar a respeito do campo sociológico americano de meados do século XX.

\section{Oliver C. Cox: um breve itinerário intelectual}

No verão de 1938, Oliver Cromwell Cox termina seu doutorado em sociologia na Universidade de Chicago. Depois de viver 19 anos nos Estados Unidos, Cox teve a oportunidade de adquirir uma formação que era invejável em seu país natal, a colônia britânica de Trinidad, no Caribe, e acreditava que isso Ihe garantiria uma 
posição de igual prestígio no campo sociológico americano. A estada nos Estados Unidos até então já havia sido marcada por infortúnios, e uma série deles ainda haveria de ocorrer até a morte do autor, em 4 de setembro de 1974.

A própria decisão de migrar para os Estados Unidos foi informada por decepções de inserção em Trinidad, embora à primeira vista pudesse ser qualificado como um "bem-nascido". Seu pai, descrito por um biógrafo do autor, Herbert Hunter, como um "mulato claro de cabelo ondulado" (Hunter, 1987), à diferença de outros importantes intelectuais trinitinos ${ }^{3}$ - como George Padmore ou C. L. R. James -, não tinha uma carreira voltada à educação ${ }^{4}$. Esses dois elementos - a ocupação e a cor - articulavam-se e estruturavam um sistema de desigualdades no Caribe colonial, e etnicidade tinha peso decisivo sobre o destino social dos sujeitos (Yelvington, 1993). Isso não significa, entretanto, que raça e etnicidade operavam da mesma maneira no Caribe como um todo, a despeito do tempo e do espaço (Hoetnik, 1985). De acordo com Daniel Segal, no caso de Trinidad, a situação de contato racial no período pré-independência era caracterizada pela existência de alguns grupos tidos como puros - europeus, africanos e indianos - e por uma grande quantidade de mestiços oriundos das várias combinações possíveis dessas três raças ${ }^{5}$. Ainda segundo o autor, raça assumia a centralidade em todas as dimensões da vida social trinitina, como um "idioma que memorava passados particulares e conectava esses passados a grupos sociais contemporâneos" (Segal, 1993: 84), e enfatiza: "as regras para a classificação de pessoas 'mestiças' eram formais e inequívocas" (Segal, 1993: 85). Nesse sistema, raça não operava como simplesmente um espelho da economia política, mas ela a representava e a configurava, o que é algo bem diferente (Segal, 1993: 83), ou, nos termos de Sylvia Wynter, esses elementos não eram em Trinidad um simples marcador de diferença de status, mas sim um sistema de valor (Wynter, 1992: 69). Isso significa que a ocupação de posições-chave para a manutenção do regime colonial e o status um pouco superior adquirido pelas classes médias de cor $^{6}$, como a família de Cox, estava intimamente associada aos trunfos morais decorrentes de traços fenotípicos e específicos, que não obstante, estavam longe de ser estáveis.

A decadência real e simbólica era um espectro sempre presente, fundamentalmente através do risco de "enegrecer" ou não conseguir acesso à educação7. O pai de Cox, embora abastado e exigente com resultados ${ }^{8}$, não conseguiu inculcar nos filhos as disposições intelectuais necessárias de acesso à educação elitista das colônias britânicas. O gosto pelo estudo havia sido passado a seus filhos, então, pelo tio de Cox, Reginald Vidale, professor e posteriormente diretor da Escola para meninos St. Thomas, onde Cox adquire a formação primária. Mas mesmo isso no caso de Cox foi insuficiente. foram traduzidos e publicados em 2015 na coletânea $A$ revolução e o negro, ampliada em 2019. George Padmore foi objeto de uma tese em 2018 (Mattos 2018). Oliver C.

Cox, por fim, possui apenas uma tradução em português de que temos notícia: o capítulo sobre estamentos de Caste, class and race, publicado em 1973 na coletânea organizada por Octavio Ianni, Teorias da estratificação social.

2. As citações em português de autores publicados em outras línguas foram traduzidas livremente pelo autor.

3. "Trinidad e

Tobago produziram muitos intelectuais de destaque, particularmente durante a primeira metade do século XX Sylvester Williams, o qual é normalmente descrito como o pai do panafricanismo; George Padmore, autor de Pan africanism or communism? entre outras obras, e outro ativista de destaque no movimento panafricano, Eugene Chen, em duas ocasiões ministro de Assuntos Exteriores no governo nacionalista da China sob Sun Yat-Sen; Eric Williams, primeiro ministro de Trinidad e Tobago de 1962 a 1981 e autor de Capitalismo e 
escravidão; Oliver Cromwell Cox, autor de Caste, class and race; C. L. R. James, entre outros." (Cudjoe, 2004: 127).

4. O pai de Cox, William Raphael Cox, após ter trabalhado como capitão de uma escuna de fiscalização da receita, destacouse na sociedade trinitina como agente de impostos do governo. Tinha, pois, uma situação financeira confortável, que garantia à família não apenas uma casa na capital, como também uma fazenda de cacau no interior da ilha que servia como casa de verão.

\section{De acordo com} Segal (1993: 85), existiam cerca de 15 permutações possíveis no sistema de consideração racial em duas gerações de uniões entre as três principais raças de Trinidad.

\section{Entre as} categorias para a classificação dos grupos emergentes do contato, deve-se destacar a de "pessoas de cor" (colored). Da mistura entre brancos e negros teria aparecido não apenas uma população de cor, mas o "mito de origem" indicava uma classe média "de cor" que preencheria o hiato social entre
Havia uma reserva das posições-chave do regime para a elite branca e colonial, e um dos modos de mantê-la era pelo controle do acesso à educação por meio de uma inflação artificial das taxas nas escolas secundárias de Trinidad (McAuley, 2004). Para famílias como as de Cox, restava a disputa pelas poucas bolsas oferecidas a alguns jovens brilhantes da colônia. Sem êxito nesses exames, não haveria alternativa educacional de qualidade, pelo menos em Trinidad. Os dois principais colégios que ofereciam formação secundária, o St. Mary's e o Queen's Royal College, e só eram acessíveis por meio das poucas bolsas que o governo garantia para toda a ilha anualmente - para o Queen's Royal College eram apenas quatro bolsas e a idade máxima para prestar o exame 12 anos (James, 1983). Oliver Cox, apesar da pesada rotina estudos exigida por seu pai e da educação repassada por seu tio, não consegue uma posição em nenhum deles ${ }^{9}$.

Esse evento explica o porquê de haver deixado o Caribe ao completar 18 anos. Após seguir os estudos em uma pequena escola agrária por um curto período tempo, enquanto trabalhava em uma loja de departamentos, Cox busca uma formação nos Estados Unidos, muito a incentivo de seu pai. Antes de partir, em 1919, dois de seus irmãos já estavam lá. O mais velho, Ethelbert, cursou medicina e o segundo, Reginald, ortodontia. Herbert Hunter comenta que os três irmãos receberam ajuda financeira, mas que apenas o primeiro a recebia enquanto ainda estudava. "Uma vez nos Estados Unidos, o jovem Oliver estava por conta própria" (Hunter, 1987: xviii). A expectativa social era que Cox seguisse alguma carreira tradicional, e assim opta pelo direito, carreira que manteria a respeitabilidade de sua origem quando voltasse ao Caribe.

Em 1919, então, Cox parte para os Estados Unidos. Por recomendação de seus dois irmãos que haviam ido antes, escolhe Chicago. Nesse momento, Chicago era um dos principais destinos para os negros que vinham do sul do país, no que foi chamada de "A grande migração". "De cidades, vilas e fazendas eles fluíram para qualquer cidade do norte onde encontrassem trabalho" (Grossman, 1989: 4). O sistema Jim Crow, a miséria, e a propaganda de periódicos como o Chicago Defender ${ }^{10}$ empurravam levas e levas de migrantes, de modo que a cidade viu sua população afro-americana passar de 44.103 em 1910 para 109.458 em 1920. "Entre as muitas cidades que ofereciam novas oportunidades de emprego, Chicago representava o destino lógico para homens e mulheres negros que se preparavam para deixar lares nas comunidades do sul" (Grossman, 1989: 4).

Isso significa que a primeira leitura de Cox sobre a América foi feita desde um lugar específico, que não é nem o sul do Jim Crow - cuja experiência posterior marcaria sua trajetória - nem a ativista Nova York, acostumada nas primeiras décadas do sécu- 
lo XX a uma intensa presença afro-caribenha e atividades políticas (Stephens, 1998). Seja como for, Chicago não era Trinidad, de modo que às classes médias negras, ainda que pudessem ascender social e simbolicamente, a segregação era evidente, e Cox irá morar na parte oeste do "cinturão negro" da cidade, até se mudar, em 1931, para a parte sul. A primeira questão com a qual teve de lidar era a de sua formação educacional. Ela era insuficiente, afinal não havia conseguido uma bolsa aos colégios de elite de Trinidad, portanto não tinha o ensino secundário. Assim, se quisesse seguir a carreira em direito, teria de voltar aos estudos básicos, e matricula-se na YMCA High School, onde se forma em 1924 e, em seguida, no Crane Junior College (ou possivelmente no Lewis Institute ${ }^{11}$. Em 1926 ingressa na Northwestern University, onde adquire em 1928 o desejado diploma que buscava quando deixou o Caribe.

Entretanto, em 1929, Cox contrai poliomielite e perde parcialmente o movimento das pernas, em um ano que passou quase que totalmente voltado a lidar física e psicologicamente com a doença. Após a recuperação, passou a depender de bengalas ou cadeira de rodas até o fim da vida. Para Cox, esse evento foi central para seu ingresso na carreira acadêmica, que, em seus próprios termos, "necessitava de menos jogo de pernas" (Cox apud Hunter, 1983: 251). Além disso, a crise econômica castigava de modo particular aqueles que estavam no cinturão negro, e em um mundo pouco afeito às pessoas com deficiência, Cox deve ter se visto empurrado para a explicação desses fenômenos. Em 1930 entra então no Departamento de Economia da Universidade de Chicago, onde adquire o título de mestre em 1932 com a dissertação Workingmen's compensation in the U.S., with critical observations and suggestions.

O mestrado injetou-Ihe preocupações intelectuais que antes não existiam. Um de seus professores no Departamento de Economia era Frank Knight. Knight era não só um weberiano em um momento raro para sê-lo nos Estados Unidos - havia publicado em 1927 a primeira tradução ao inglês de um livro de Weber, História econômica geral (Emmett, 2006.) -, mas quando se torna membro de Departamento de Economia da Universidade de Chicago, passou a "intensificar, ao invés de diminuir, seu interesse em Weber e história comparativa" (Emmett, 2006: 107) ${ }^{12}$. Ademais, tinha uma concepção particular a respeito do papel das ciências sociais que pode ter impactado Oliver C. Cox, na medida em que esse parece ter sido o efetivo contato inicial do autor com a área. "A preocupação primordial de Knight era a articulação de uma ciência social (não apenas econômica) que poderia resolver as tensões centrais da modernidade" (Emmett, 2006: 103).

Não é estranho, pois, que Cox se decepcione com as ferramentas explicativas da economia e opte pela sociologia para tentar encontrar um sentido para Grande as classes altas (brancas) e baixas (negras) (Segal, 1993)

7. Chave aqui está a questão da "respeitabilidade". C L. R. James comenta o peso que esse fator social teve sobre sua própria trajetória, fazendo notar o esforço que sua família fez para conquistá-la, desde os tempos de seu avô paterno, que ia sob o sol escaldante do Caribe à escola dominical lecionar de fraque, cartola e bengala, até ele próprio, autodefinido como "um intelectual britânico muito antes dos dez anos". (James, 1983: 28).

8. De acordo com Herbert Hunter, o pai de Cox exigia uma pesada rotina de estudos de seus filhos. Essa rotina envolvia despertar cedo todos os dias, banhos gelados e estudos antes de irem para a escola (Hunter, 1983: 250).

9. Por outro lado, C. L. R. James, outro trinitino que nasceu no mesmo ano que Cox, 1901, é aprovado em 1910 em primeiro lugar, e torna-se o mais jovem a conseguir uma das bolsas. (James, 1983; Buhle, 1988).

10. "O Chicago Defender, jornal mais amplamente lido no sul negro, proporcionava vislumbres de uma cidade empolgante 
e com uma população negra vibrante e assertiva a milhares de possíveis migrantes." (Grossman, 1989: 4).

\section{Há aqui} um conflito de informações entre os dois principais biógrafos e comentadores da obra de Cox. De acordo com Herbert Hunter, Cox teria se formado no YMCA em 1923 e em seguida adquirido uma formação complementar no Lewis Institute com ênfase em história e economia em 1925 (Hunter, 1983: 250). Christopher McAuley afirma que a presença de Cox no Lewis Institute se deu apenas por uma licença de estenógrafo (McAuley, 2004: 243). Essa informação decorre de um formulário escrito pelo próprio Cox, já no fim de sua vida, no qual não se menciona nem o Lewis Institute nem que se formou em 1923. Para McAuley, Cox teria estudado brevemente no Crane Junior College (hoje Malcom X College). Outro conflito de informação diz respeito à data de ingresso de Cox no curso de direito da Northwestern. Hunter, em 1983, afirma que Cox ingressa em 1926 e termina em 1928, mas 1987, afirma que Cox ingressa em 1927 e termina em 1929 (Hunter, 1987: xix). Como McAuley
Depressão ${ }^{13}$. O estranho é ele ter esperado encontrar na sociologia de Chicago mecanismos explicativos da crise, em relação ao que de fato a sociologia de Chicago poderia oferecer à época. Era uma sociologia voltada para problemas de pesquisa distantes das preocupações macroestruturais que pareciam animar Cox, além do que as perspectivas interpretativas tampouco enfatizavam elaborações teóricas dessa natureza. "A sociologia de Chicago caracteriza-se antes de tudo pela pesquisa empírica [...]. A Escola de Chicago é uma sociologia urbana, que realizou uma série impressionante de estudos sobre problemas que enfrentava a cidade" (Coulon, 1995: 7-8).

O departamento, entretanto, era mais diversificado do que, por vezes, se costuma apresentá-lo. De acordo com Howard S. Becker:

\begin{abstract}
A Escola de Chicago nunca foi uma escola no sentido pleno. Como Jennifer Platt deixou bem claro, Chicago, a verdadeira Chicago na 59a Rua, no prédio de ciências sociais, em oposição à Chicago do mito de origem, era muito mais variada e diferenciada que isso. Park, Burgess, e Ellsworth Faris, as pessoas agora comumente acreditadas de terem incorporado a grande tradição de Chicago durante os anos 20 e 30, foram de início juntadas a Ogburn, que tinha uma visão bem diferente da sociologia e de sua missão (Becker, 1999: 4-5).
\end{abstract}

Nesses interstícios é possível compreendemos a inserção de Cox. Relações raciais faziam parte da produção da sociologia de Chicago - chegando mesmo a configurar o que é por vezes chamado de uma Escola de Chicago de Relações Raciais (Deegan, 2008a) -, e Cox, evidentemente, cursou disciplinas nesse campo, todas ${ }^{14}$ ministradas por Robert Ezra Park (Johnson, 2004: 103). Porém, mais importante, Cox não foi orientado por Park ou outra "figura emblemática" como Ernest Burgess, como foi a tendência entre outros membros do que Young Jr e Deskin chamam de "segunda onda da tradição inicial de pensamento sociológico afro-americano"15. Cox foi orientado por William F. Ogburn.

A visão e a missão da sociologia de Ogburn, destacada acima por Becker, contrastava com o restante do Departamento justamente pela ênfase na pesquisa quantitativa ${ }^{16}$, motivo pelo qual fora justamente contratado, e deixou a Universidade de Columbia. Assim, a tese de doutorado de Cox, Factors affecting the marital status of negroes in the United States, foi um trabalho cujo material é essencialmente estatístico, e que revela sua "atração pelos métodos quantitativos enfatizados por Ogburn e Samuel Stouffer, ao invés dos métodos mais qualitativos de estudo de caso ou abordagem ecológica desenvolvidos por Park, Burgess, Blumer e seus alunos" (Hunter, 1987: xxi). 
Não obstante, Cox manifestava reservas quanto ao papel exercido por seu orientador, Ogburn, e outros professores do departamento em matéria de relações raciais. Cox os via como figuras paternalistas, que, embora progressistas, se opunham à tomada de iniciativa pelos próprios negros em movimentar a questão racial em um ritmo mais rápido (Johnson, 2004). Importante dizer que a relação de Cox com os pares negros em Chicago também parece ser conturbada ${ }^{17}$. Na seção seguinte, voltaremos ao tema da relação de Cox com a Escola de Chicago.

Cox termina então seu doutorado em 1938. Como era costume, os sociólogos negros, por melhor que fossem suas qualificações, encontravam emprego apenas em instituições negras, onde a carga de trabalho era alta e a remuneração baixa. Isso era regra para a primeira geração de sociólogos negros (Young Jr. \& Deskin, 2001; Keys, 1978) - da qual podemos destacar Du Bois -, e permaneceu, com algumas exceções como Allison Davis e St. Clair Drake, do mesmo modo para a segunda geração ${ }^{18}$. Dos que passaram por Chicago, Charles S. Johnson e Horace Cayton Jr. foram para Fisk, e E. Franklin Frazier foi para Fisk e, posteriormente, Howard. Oliver C. Cox conseguiu emprego na pequena faculdade metodista de Wiley, em Marshall, Texas.

Wiley é importante para o que nos interessa neste artigo por dois motivos principais. O primeiro reporta-se ao relativo isolamento da faculdade das fontes de financiamento de fundações que, no entre-Guerras, passaram a se interessar cada vez mais por pesquisas em temáticas raciais realizadas em "instituições seguras e dependentes", que pudessem ser confiadas para conduzir pesquisas sobre problemas negros sem desafiar as atitudes raciais dominantes à época (Stanfield, 1982: 199) ${ }^{19}$. O segundo motivo, e mais evidente, diz respeito a Wiley encontrar-se no sul, o que permitiu a Cox uma compreensão muito distinta das relações raciais, compreensão essa que pode ajudar a explicar o porquê da rebelião do autor contra o establishment sociológico americano que culminaria em sua efetiva exclusão.

A tese de doutorado de Cox e seus escritos até 1942 não manifestavam o tom radical pelo qual o autor seria futuramente conhecido, e os artigos que publica até então ainda se voltam àquele tema ou a temas correlatos ${ }^{20}$. O que leva o autor em 1942 a publicar sua primeira crítica significativa aos fundamentos da sociologia das relações raciais americana? É possível que a temporada em Wiley permitiu a Cox uma compreensão muito distinta sobre o sistema de segregação do sul, algo que somado ao senso de si desenvolvido no Caribe sustentado pela respeitabilidade, abalou sua postura diante do tom não conflituoso, conciliatório e acomodatício do tipo de pesquisa que se desenvolvia em Chicago. É também plausível considerar que Cox esperasse uma garantia, devido à sua formação, de um lugar mais prestigioso do que aquele que havia conquistado no campo sociológico americano, como os de Frazier ou Charles S. Johnson. também opta por 1926 como o ano de ingresso e 1928 como de término, esta será a cronologia adotada aqui.

12. "Entre

1929 e 1932,

Knight escreveu aproximadamente 25 resumos de livros e artigos de historicistas alemães para o Social Science Abstracts, uma tentativa de curta duração (quatro volumes entre 1929-1932) de proporcionar acesso à literatura europeia a cientistas sociais norte-americanos." (Emmett, 2006: 107)

\section{3. "Senti que se} a economia não explicava o que eu queria saber; se a Economia não explicava a chegada da depressão; se a economia não me ajudava a entender aquela grande mudança econômica então senti que não precisava dela. Assim, mudei para a sociologia" (Cox apud Hunter, 1983, p. 251).

14. Há uma imprecisão no tocante ao curso "Negro in America", se foi ou não ministrado por Park na primavera de 1935 (Johnson, 2004).

15. "Algumas das condições particulares à segunda geração de sociólogos afroamericanos que não se faziam presentes na primeira eram: 
uma preocupação menor em refutar os argumentos racistas do final do século XIX e início do XX; uma preocupação mais específica com as condições e os efeitos do urbanismo, integração, pobreza rural e segregação sobre a psique individual e comunitária de afro-americanos; adaptação mais completa aos métodos e paradigmas sociológicos padrões; inclinação maior a enfatizar a noção de pesquisa científica contemporânea ao invés de teorização abstrata; um tanto menos de envolvimento em ações de protesto ou política; e uma aceitação um pouco maior pela comunidade sociológica formal. Em grande parte, a emergência desses fatores se deve à conexão de muitos destes acadêmicos com Robert Ezra Park e a Escola de Sociologia de Chicago" (Young et Deskin, 2001; 461).

\section{6. "Ao chegar à} Universidade de Chicago, encontrei uma atitude muito mais hostil em relação à estatística do que eu havia encontrado em Columbia. Mas lutei a batalha, lecionei todas as estatísticas no Departamento de Sociologia e geralmente participei do trabalho estatístico dos comitês da
Durante a temporada em Wiley - e posteriormente no Tuskegee Institute, a partir de 1944 - até a publicação de sua magnum opus Caste, class and race, em 1948, Cox publica cerca de onze artigos críticos ao que chama de "Escola de castas de relações raciais" e a outros grandes nomes das ciências sociais americanas contemporâneas, como Ruth Benedict e Robert Park. O livro Caste, class and race, que incorpora e reorganiza as críticas dos artigos anteriores, termina por selar o destino social do autor. Foi enterrado pela editora Doubleday um ano após o lançamento, assim que esgotada a primeira impressão (Sweezy, 1987), e Cox produziu escritos tão impopulares nos "anos 1950 e 1960 que foi obrigado a pagar $\$ 2.000$ e \$2.500, respectivamente, para ter The foundations of capitalism e Capitalism and American leadership publicados" (Hier, 2001: 72). A afirmação de Herbert Hunter (1983), de rotular Cox como um "sociólogo esquecido", faria sentido.

O que nos chama atenção hoje, à primeira vista, é o fato de em 2006 a Associação Americana de Sociologia modificar o título do prêmio que dá a trabalhos em relações raciais em para Cox-Johnson-Frazier Award ${ }^{21}$, em homenagem a Cox, o primeiro a recebê-lo, em 1971, como se estivesse a corrigir uma injustiça histórica. Ou a celebração de sua obra por parte de autores consagrados como Immanuel Wallerstein ${ }^{22}$ ou o antropólogo Louis Dumont ${ }^{23}$. Acreditamos que o que permitiu a Cox ser celebrado décadas após sua morte e também o esforço ativo para sua anulação ainda em vida é decorrente de um elemento particular de sua trajetória, o que chamamos, a partir de Stuart Hall (2007), de o prisma de sua formação caribenha. Pretendemos, na seção seguinte, lançar uma hipótese sobre esses movimentos.

\section{Os desprazeres do exílio e um prisma para a sociologia dos intelectuais}

Na seção anterior, tentamos evidenciar os principais aspectos que baseiam nossa proposta de interpretação acerca de alguns problemas que cercam a trajetória de Oliver C. Cox, e quais os impactos dessa interpretação sobre as estruturas de diálogo da sociologia e as narrativas disciplinares. Em se tratando de Cox, o que parece mais importante para nós aqui concerne à circulação internacional. Gisèle Sapiro destaca que a circulação internacional é largamente determinada pelas relações de força entre países centrais e periféricos (Sapiro, 2013) e, nesse cenário, a situação colonial na primeira metade do século XX é sintomática. É difícil falar de intelectuais afro-caribenhos sem falar na experiência do exílio. Gerações de pensadores, ativistas, poetas e escritores das Índias Ocidentais se viram obrigados a deixar suas terras, muitas vezes para nunca mais regressar, e esses deslocamentos se refletiram em suas obras e projetos. Cox não foi de maneira nenhuma exceção, mas regra. 
Essa experiência, embora de longe não seja única aos afro-caribenhos, foi no caso particular destes também condicionada por um problema adicional e, em nossa leitura, ainda mais fundamental. Essa circulação significava também uma circulação por distintas gramáticas de racialização. Com este termo, enfatizamos ao mesmo tempo o caráter processual de raça, refletido por Frantz Fanon (2008) por meio do termo "racialização", e a dimensão significante que ela assume, conforme ressalta Rita Segato:

Raça é signo e, como tal, depende de contextos definidos e delimitados para obter significação, definida como aquilo que é socialmente relevante. Estes contextos são localizados e profundamente afetados pelos processos históricos de cada nação. [...] Um afro-norte-americano é um sujeito muito diferente de um sujeito classificado negro no ambiente social brasileiro. Todas estas sociedades pós-coloniais do continente americano são moduladas por uma forte estratificação etnicorracial, mas a engenharia desta estratificação é variável (Segato, 2005: 6).

Devemos nos perguntar o que ocorre aos sujeitos ao circularem e se deslocarem entre essas diferentes gramáticas, e se tal circulação, no caso de intelectuais, têm qualquer efeito sobre suas produções. Para Stuart Hall, ela é determinante. Hall destaca em um evento realizado em sua homenagem que sua visão do que poderia ser visto como "problemas ingleses" está baseada em outro lugar, lugar esse que decorre do fato de estar "na diferença" (Hall, 2007) ${ }^{24}$. Hall chama esse "outro lugar" de "o prisma de sua formação caribenha". Percepções similares podem ser encontradas em diversos outros intelectuais da região ao discutirem suas próprias trajetórias e aquelas de outros conterrâneos ${ }^{25}$. O significado desse prisma, seu significado sociológico é, contudo, menos explorado.

O fato de Cox ter nascido e crescido no Caribe não é frequentemente considerado (McAuley, 2004). Christopher McAuley é um autor que se atenta ao fato, e tenta compreender a evolução do pensamento de Cox em estreita concordância com seu plano de fundo caribenho.

O quadro de referência caribenho de Cox é precisamente o componente de suas análises que faz seu ponto de vantagem tão importante e oportuno: o dele é uma perspectiva inicial de "Terceiro Mundo" sobre os problemas mais urgentes de nosso tempo - globalização capitalista, conflito étnico e o futuro das relações sociais (McAuley, 2004: 3)

Embora se proponha a dar atenção a essa faceta, o livro de McAuley não desenvolve os nexos causais entre a trajetória social caribenha e a produção sociológica de
Universidade"

(Ogburn apud Laslett 1991: 516).

17. Essa mesma crítica, Cox a dirigia a seus pares negros, em Chicago. Yolanda Johnson afirma que "a principal queixa de Cox à respeito tanto de Johnson como de Frazier era a aceitação por estes da atitude paternalista de Park com relação a estudantes afro-americanos" (Johnson, 2004: 107)

18. O recorte geracional para a interpretação das presenças afro-americanas na sociologia aparece em diversos autores, em particular Young Jr. \& Deskins Jr. (2001), Bowser (1981) e Keys (1978)

19. Sociólogos eram igualmente dependentes de sua adesão à manutenção da ordem racial

"Os conselhos administrativos e especialistas em raça das fundações tinham um desdém por pesquisas em raça e acadêmicos negros radicais. Os especialistas em raça das fundações não apoiavam avaliações críticas acerca de problemas de ajustamento negros (por exemplo a exploração político-econômica branca)..." (Stanfield, 1982: 201)

20. Entre 1940 e 1942 Cox publicou 
"Farm tenancy and marital status"; "Sex ratio and marital status among negroes"; "Sex ratio and marriages in rural communities"; "provisions for graduate education among negroes"; "Employement, education and marriage of young negro adults".

21. O título antes era DuBois-JohnsonFrazier Award. Para informações sobre o prêmio, consultar: <http://www.asanet. org/news-events/ member-awards/ cox-johnson-frazierasa-award>

22. "Oliver C. Cox expôs nos anos 50 e 60 virtualmente todas as ideias básicas de uma análise do sistemamundo. Ele é um pai fundador, mas um pai fundador que dificilmente é reconhecido como tal e amplamente negligenciado, mesmo hoje." (Wallerstein, 2000: 174).

23. "A crítica à "Escola de castas de relações raciais" foi notavelmente levada adiante por Oliver C. Cox. A partir das mesmas fontes que Warner, Cox, com insight admirável, desenvolveu uma imagem do sistema de castas que é infinitamente mais verdadeira do que aquela com a qual Warner se satisfazia. É verdade que não se pode concordar em todo lugar com
Cox, além da afirmação de que isso o fez um "comparatista social natural" (McAuley, 2004: 2). Essa própria afirmação, caso verdadeira, tampouco deixa claro o que há de particularmente notável no comparatismo de Cox que o distinga de seus pares, na medida em que o mundo acadêmico norte-americano ao qual Cox seria posteriormente exposto também gerou sua própria leva de comparatistas como, desde um ponto de vista mais formal, Melville Herskovits, e desde um ponto de vista mais geral, as gerações de intelectuais negros americanos que se viram forçados a iniciar as reflexões acerca de suas experiências não na América, mas sim na vida e nas instituições africanas ${ }^{26}$. O Caribe, assim, aparece às vezes como um atalho explicativo que foge das entrelinhas de influências mais diretas sobre o autor na América.

Na linha das influências mais diretas, por sua vez, encontramos outro modo de abordar a questão, que repousa naqueles comentadores que deram atenção à experiência do racismo, de como situações distintas de contato racial geram tipos de disposições que impactam o destino social dos sujeitos. Sobre Oliver Cox, o biógrafo Herbert Hunter diz:

A experiência de crescer nas Índias Ocidentais sob o regime coIonial britânico nas primeiras duas décadas do século XX garantiu a Oliver Cox uma herança cultural que seria única entre os sociólogos americanos negros de sua geração. Em Trinidad, Cox estava muito distante da discriminação racial e da hostilidade que caracterizavam as relações raciais nos Estados Unidos e, além disso, teve a experiência de viver em um país onde os brancos eram uma minoria e considerados estrangeiros. [...] Sem restrições legais explícitas ou uma barreira de cor rigidamente definida separando as raças, havia oportunidades para trinitinos que tivessem a cor de pele apropriada, riqueza, educação e/ou status familiar - era a interligação desses fatores que configurou o padrão de poder e privilégio na população nativa (Hunter, 1987: xviii).

Em um texto comparativo entre Cox e o sociólogo E. Franklin Frazier, Anthony Cheeseboro corrobora:

Muitos acadêmicos notam que Cox foi exposto a relativamente pouco racismo quando era criança, como havia nascido e sido criado entre a maioria afro-caribenha de Trinidad, e que isso foi muito importante em formar sua abordagem às questões de raça (Cheeseboro, 1999: 162, grifo nosso).

O que isso significa, Cheeseboro não explora.

De fato, a situação de contato racial em Trinidad era muito distinta da situação norte-americana, e provavelmente Cox em sua ida aos Estados Unidos enfrentou 
dificuldades em negociar o mundo que o criou com o mundo que agora o recebia e Ihe fechava as portas - ou lhe apresentava a porta dos fundos (Winston, 1971). O problema com a ênfase desse aspecto, para os fins de nosso trabalho, encontra-se na ponte analítica entre a experiência do racismo e os aspectos tanto formais quanto de conteúdo da produção acadêmica de Cox, nos vínculos entre trajetória social e produção intelectual. Ou seja, quão modelador e radical esse aspecto particular da trajetória pode ter sido? É razoável esperar que um "ponto de vantagem oportuno" ancorado em uma experiência subjetiva diferente do racismo que fosse assim perceptível permitiria que a obra de Cox fosse interpretada primordialmente por esse crivo, tal como ocorre, por exemplo, em Fanon (2008) - que faz desse deslocamento o ponto de partida de suas reflexões. Pelo contrário, o próprio Christopher McAuley comenta, acerca da formação caribenha de Cox, que essa perspectiva a ressaltar a centralidade da formação caribenha do autor, embora

dificilmente notável, é indiscutivelmente não partilhada por muitos que estão familiarizados com seu [Cox] trabalho", [e completa:] No curso de minha pesquisa fui repetidamente surpreendido pelo número de acadêmicos americanos que ou falham em considerar, ou que dispensam por omissão, seu plano de fundo caribenho, e por aqueles acadêmicos caribenhos que em grande parte 0 interpretam como um afro-americano (McAuley, 2004: 2).

Mary Jo Deegan considera que a vida de Cox é reveladora, de como a marginalidade molda carreiras e ideias (Deegan, 2000: 284). No que diz respeito ao papel do Caribe e da raça, Deegan recorre ao que chama de "o véu da sociologia americana". Esse recurso tem origem na metáfora de W. E. B. Du Bois em As almas da gente negra. De acordo com Du Bois, as relações entre os afro-americanos e o mundo são mediadas por um "véu" que, por sua vez, gera uma dupla consciência.

É uma sensação estranha, essa dupla consciência, essa sensação de estar sempre a se olhar com os olhos de outros, de medir sua própria alma pela medida de um mundo que continua a mirá-lo com divertido desprezo e piedade. E sempre sentir sua duplicidade - americano e Negro; duas almas, dois pensamentos, dois esforços irreconciliados; dois ideais que se combatem em um corpo escuro cuja força obstinada impede unicamente que se destroce (Du Bois, 1999: 54).

De acordo com Deegan, essa duplicidade da experiência negra definiria um padrão de atitudes - e também, como consequência, uma epistemologia específica - às quais os sociólogos afro-americanos, particularmente no Departamento de Sociologia de Chicago, tinham que submeter para avançar em suas carreiras. No entanto, para Deegan, essa duplicidade - na mesma direção que as tendências que
Cox, mas devemos lembrar que ele estava trabalhando com fontes de segunda ou mesmo terceira mão (por exemplo: Bouglé)" (Dumont, 1980: 254-255)

24. Em outro texto, de 1998, Stuart Hall afirma que "esse é o paradigma da experiência diaspórica. O fato claro é que eu me tornei 'negro' em Londres, e não em Kingston" (Hall, 1998: 190).

25. Frantz Fanon (2008) faz dessa experiência o ponto de partida para parte significativa de suas reflexões em Pele negra, máscaras brancas. Talvez a reflexão mais clássica sobre o tema apareça em The pleasures of exile, de George Lamming. Publicado em 1960, em uma passagem Lamming resume a experiência de se descobrir como parte de algo maior na Inglaterra: "nenhum barbadiano, nenhum trinitino, nenhum santa-lucense, nenhum ilhéu das Índias Ocidentais vê a si próprio como indiano ocidental até ele encontrar outro ilhéu que nasceu em um território estrangeiro [...] nesse sentido, a maior parte dos indianos ocidentais de minha geração nasceu na Inglaterra." (Lamming, 1992: 214). Stuart Hall, por sua vez, recorda também ter se 
descoberto como negro na conjuntura específica da Inglaterra dos anos 60 (Hall, 2010).

26. A concepção original dos estudos negros "tratou africanos e descendentes de africanos pelo globo como um só povo (diverso e complexo, é claro) [...], e é precisamente essa perspectiva de ver o povo negro em termos globais que forçou o campo a ser implacavelmente internacional e comparativo" (Kelley, 1999: 1046). mencionamos anteriormente sobre a intensidade do racismo -, estaria ausente no Caribe natal de Cox:

\begin{abstract}
Embora Cox tenha sido tratado como um afro-americano nos Estados Unidos, ele era um afro-caribenho americano. Ele não nasceu nessa "duplicidade no interior do self". Suas experiências diferentes de infância Ihe deram uma abordagem crítica que fez da raça um tópico de relevância que diferia daquela de seus colegas nascidos nos Estados Unidos, e o sistema de relevância de Cox está refletido em sua produção (Deegan, 2000: 280).
\end{abstract}

O problema aqui, como nas abordagens anteriores, está na ênfase da explicação - a suposta intensidade menor de racismo no Caribe, seja o que for que isso signifique, e qual a relação disso com as ideias.

Reconhecer essa dimensão na circulação internacional de Cox, que tratamos aqui como prisma de formação caribenha, pressupõe, em primeiro lugar, necessariamente o reconhecimento da dinâmica opressiva de raça ao qual o autor esteve submetido tanto em casa como no estrangeiro. Entretanto, a ênfase para os fins deste trabalho não está tanto no Caribe em si, ou mesmo nos Estados Unidos em si, mas na circulação a partir daquele para este. C. L. R. James parece ter notado algo interessante quando afirma - mesmo sem conhecê-lo pessoalmente, ao que tudo indica (Reddock, 2014; Montañez Pico, 2018) - que Cox era "americano em suas atitudes" (James, 2016). Codificar a discussão acerca da experiência racial e sua influência sobre Cox em termos de intensidade (ao se tratar mais ou menos racismo), como comumente é feito, deixa escapar o que há de mais fundamental, a saber, os processos subjetivos que são gerados na transição entre uma e outra gramática de racialização em ambos os contextos.

Ademais, é importante dizer que a perspectiva da "intensidade do racismo" é decorrente de um enquadramento que isola o fator racial como elemento adicional que incide sobre a experiência de intelectuais afro-diaspóricos, um enquadramento que não encara a dimensão integralmente estruturante do mundo social que raça assume enquanto discurso (Hall, 2017a). Nessa perspectiva, tem-se raça como tema a ser tratado sociologicamente, mas sem competência para impactar ou desafiar as estruturas de diálogo da disciplina (Bhambra, 2007). A perspectiva do prisma aqui proposta, por sua vez, vai em direção oposta. Trata-se de colocar aquilo que poderia aparecer como uma disfunção no princípio da explicação, conforme aponta Stuart Hall:
Embora eu ache produtivo pensar em termos de uma diáspora, o conceito de diáspora pode certamente ser usado para exatamente 
o fim oposto: não para confrontar, mas para disfarçar, evitar ou reprimir tais tipos de dinâmicas emocionais internas e os traumas resultantes envolvidos. O grande valor do pensamento diaspórico, tal como eu o concebo, é que longe de abolir tudo que se recusa a encaixar ordenadamente em uma narrativa - os deslocamentos coloca as disfunções em primeiro plano (Hall, 2017b: 171).

Desse modo, é a experiência da circulação internacional e entre gramáticas distintas de racialização que importa, e mais pelo processo em si do que por sua resolução, ou mesmo seu início. Isso significa dizer que Cox dificilmente poderia ter escrito o que escreveu se tivesse permanecido no Caribe, e não apenas devido ao mais evidente fator do acesso ao universo acadêmico americano. Os intelectuais afro-caribenhos vinham da periferia de processos sociais e se deparavam com a real natureza de sua sujeição, seja de suas terras natais ou de onde passaram a residir, nesses novos contextos.

Não se trata exatamente de "descobrir o verdadeiro racismo nos Estados Unidos", mas sim o fato de tal experiência revelar o caráter eminentemente volátil que marca as relações raciais, algo que aliado à sua trajetória intelectual, criou em Cox as condições para a produção de um ponto de vista heterodoxo insurgente, que visa desafiar os mecanismos intelectuais da opressão (Morris, 2015). O caráter volátil dessas relações foi, assim, evidente para Cox e ocupou um lugar central em seus escritos, principalmente após mudar-se para o sul dos Estados Unidos. Essa percepção aparece em Caste, class and race de maneira manifesta quando o autor discute, no capítulo 17, o que define como situações de relações raciais. Para Cox, elas seriam sete, e existiriam apenas dentro de um sistema social mais geral: a classe ${ }^{27}$. Mas essa percepção também aparece em uma dimensão mais epistemológica, que permitiu a Cox contestar a dominante Escola de Castas de Relações Raciais - que ele próprio assim denomina. Os autores dessa perspectiva, cujo principal grupo articulava-se ao redor de Lloyd Warner, em Chicago, importaram a categoria "casta" de seu uso no caso indiano para tentar explicar o padrão assimétrico de relações raciais no sul. De acordo com McKee (1993), aqui apresenta-se uma atualização do compromisso da sociologia americana com a manutenção da ordem racial. Isso foi percebido por Cox na década de 1940:

Ao usar uma hipótese de castas, então, a Escola [de castas] busca explicar uma "sociedade normal" no sul. Em resumo, deu paz a uma sociedade híbrida que não assegurou harmonia para si própria; e enquanto isso for verdade, o trabalho é ficcional (Cox, 1948: 504).

Assim, a utilização de casta implica em levar a discussão para longe da política e em direção à cultura. As relações raciais passam a ser algo não reformável por estarem
27. Diferentemente de Talcott Parsons, para quem os sistemas sociais são "abstratamente definidos com relação ao comportamento concreto de interação social" (Parsons, 1974: 15), para Cox os sistemas sociais significam um mundo social realmente existente. Para o autor, a identificação de seus traços fundamentais permite a esses sistemas serem classificados. Os três sistemas são fundamentalmente casta, estamento e classe - raça não configurando um sistema (Cox, 1948). 
28. Allison Davis, em sua resenha crítica ao livro de Cox, não deixa de mencionar que Cox não cita $O$ capital em Caste, class and race, mas apenas Contribuição à crítica da economia política e $\mathrm{O}$ manifesto comunista "De fato, Dr. Cox demonstra apenas um conhecimento superficial de Marx, dando a entender que descobriu as ideias de Marx independentemente, não inclui Das Kapital em sua bibliografia e lista apenas as traduções em inglês de Marx" (Davis, 1948: 161).

\section{Nunca um} acadêmico. O mais próximo disso a que chegou corresponde talvez ao breve período que lecionou no Federal City College, hoje University of the District of Columbia, durante a década de 1970. C. L. R. James foi deportado dos Estados Unidos em 1953, devido às suas atividades políticas.

\section{Howard P.} Becker respondeu a Cox em uma carta: "Depois de uma profunda busca e uma meticulosa segunda leitura de seu manuscrito, sou forçado a dizer que me é absolutamente impossível escrever uma introdução ao seu livro que não faça mais mal do que bem. Seu marxismo é tão não diluído, especialmente na parte sobre classe e na conclusão, distantes do tipo de problemas que estão sujeitos à intervenção, e quando a hipótese de castas é extrapolada para diferentes tipos de sociedade, a tensão política da teoria se intensifica e se escancara:

\begin{abstract}
Se temos castas entre negros e negros no Haiti, entre pessoas de cor na Índia e entre brancos e brancos na Inglaterra, então há mais do que razão e justificação para se ter casta entre brancos e negros no sul. A implicação da "naturalidade" da casta fornece uma confortável suposição geral (Cox, 1948: 544).
\end{abstract}

A contestação de Cox a essa escola, por outro lado, selou seu destino social, principalmente pela maneira como foi feita. Uma importante influência para a escrita do livro foi a obra de Marx, e embora a leitura de Cox dessa literatura fosse profundamente limitada nesse momento - algo inclusive observado por seus opositores $^{28}$-, foi mais que suficiente para rotulá-lo. De fato, na aurora no macarthismo, ser comunista não era algo a ser recompensado, principalmente no tocante às possibilidades de inserção acadêmica, fosse esse marxismo uma ferramenta analítica, como no caso de Cox, ou um comprometimento político, como no caso de C. L. R. James ${ }^{29}$. Essa fórmula pareceu perigosa para os pares de Cox, e o autor pagou o preço quando a utilizou para atacar os preceitos que sustentavam as reflexões em relações raciais. As resenhas imediatas à publicação de Caste, class and race (Hill, 1948; Blizzard Jr., 1948; Davis, 1948; Hughes, 1948) criticaram sua linha. Howard P. Becker se recusou a escrever a introdução do livro por suas "tendências comunistas" 30 , e os editores se recusavam a publicar os trabalhos de Cox pelos mesmos motivos ${ }^{31}$. Um deles, William Selgby, respondeu em uma carta: "Caro professor Cox. É inútil, não consigo digerir a linha comunista" (Selgby apud Martin, 1971: 22).

Entretanto, parece-nos que o comunismo de Cox está articulado a algo mais fundamental. A perspectiva de que o autor foi enterrado pelo seu alinhamento deve ser vista com algumas ressalvas. Outros autores contemporâneos a Cox, negros e brancos, também tinham tendências marxistas e não tiveram o mesmo destino. Para fins de comparação, E. Franklin Frazier, negro que passou por Chicago, também partilhava a influência da análise dialética marxista, de acordo com Anthony Cheeseboro. No entanto, Frazier optou por dissimular sua influência, mesmo quando fazia críticas que eram claramente marxistas - como em Black bourgeoisie ${ }^{32}$.

A principal diferença na estatura acadêmica dessas duas importantes figuras pode ser atribuída a suas abordagens diferentes dos paradigmas aceitos por acadêmicos estabelecidos em seus campos. Cox desafiou diretamente esses paradigmas, enquanto a abordagem de Frazier era mais oblíqua (Cheeseboro, 1999: 150). 
A questão, então, parece estar no lugar para a crítica que se reservava aos intelectuais negros.

Deegan segue o mesmo caminho, ao sublinhar a reação de Cox ao véu da sociologia de Chicago:

Cox experenciou o véu da sociologia, mas ele não se acomodou a ele, nem no segmento branco nem no afro-americano da Escola de Chicago de Relações Raciais. A recusa de Cox em adaptar-se à Escola de Chicago branca o separou de seus colegas afro-americanos de Chicago de maneira fundamental. [...] Muitos dos primeiros afro-americanos que foram treinados no segmento inicial da Escola de Chicago de Relações Raciais também seguiram a visão acomodatícia de Park e [Booker T.] Washington... (Deegan, 2000: 280).

Assim, não é uma questão exclusivamente racial nem especificamente de filiação política que explica a marginalização de Cox, mas sim uma articulação desses elementos, e vale dizer que tampouco esses elementos em si dispuseram Cox a tomar posição contra o lugar que lhe era designado - o fato de ter sido um negro caribenho a fazê-lo, e não americano, precisa ser melhor apreciado ${ }^{33}$. Sean Hier contrasta em um trabalho os resultados dos desenvolvimentos sobre o sistema-mundo de Wallerstein e Cox. Depois de um escrutínio crítico sobre as contribuições de ambos, indica que o marxismo não foi sozinho a principal variável. Wallerstein bebeu da mesma água, e embora se possa objetar que o ambiente dos anos 60 e 70 dos Estados Unidos fosse mais aberto a ideias radicais, ainda sim recebeu um reconhecimento muito maior. Cox foi lido como um comunista, era negro e rebelou-se contra o establishment sociológico em sentido amplo; tanto contra o arcabouço estrutural-funcionalista que sustentava o edifício da teoria estratificação social ${ }^{34}$ - que apresentava esta como um fato normal e necessário nas sociedade humanas - quanto a posição, fortemente presente na Chicago dos anos 40, da dissociação entre valores e ciência (Hier, 2000: 301). "A rigidez das barreiras raciais era equiparada à rigidez das barreiras intelectuais. Cox tentou quebrar ambas" (Hier, 2001: 83). Se Cox tivesse escrito suas críticas em outro momento, teria o mesmo destino? É difícil saber. As atividades socialistas entre negros americanos durante as décadas de 60 e 70 tampouco foram mil maraviIhas, basta observar as experiências de movimentos como os Panteras Negras ou de intelectuais como Angela Davis e a controvérsia sobre sua expulsão da Universidade da Califórnia em 1969-1970. Além disso, ativistas e intelectuais negros posteriores não perdoaram a solução assimilacionista promulgada por Cox desde os anos 40, o que complicou sua situação. Como diz Barbara Celarent, Cox foi então "pego pela letargia reputacional: muito fora de moda para ser ativamente debatido, muito ultrapassado para ser retrospectivamente imortalizado" (Celarent, 2011: 1664). que eu teria que me dissociar completamente de tais proporções." (Becker apud Hunter, 1987: xxxiii).

31. Para maiores informações sobre a acusação de comunismo contra Cox, consultar a segunda parte da dissertação de Elmer Martin (1971).

32. No mesmo ano da publicação de Caste, class and race, 1948, Frazier torna-se presidente da então Sociedade Americana da Sociologia (hoje Associação Americana de Sociologia).

33. "A comunidade étnica caribenhoamericana produziu algumas das figuras mais influentes nas políticas racial e cultural americanas ao longo do século XX, figuras que vão de Marcus Garvey e Claude McKay, passando por Harry Belafonte, C. L. R. James, Stokeley Carmichael e Bob Marley, além de autores contemporâneos como Paule Marshall e Jamaica Kincaid" (Stephens, 1998: 593).

34. Um exemplo dos usos do termo estratificação na sociologia americana do anos 40 pode ser apreciado em: Alguns princípios de estratificação (Davis \& Moore, 1969). No artigo, os 
autores advogam a necessidade funcional da estratificação social. Para Moore e Davis, casta, classe etc. são sistemas de estratificação específicos, e que se relacionam às diferentes formas de ordenação das desigualdades em diferentes sociedades. Devese enfatizar que a abordagem da "estratificação social" era difundida nos debates sociológicos da época, tornando difícil afirmar uma unidade geral de sua aplicação, embora seja muito associada à produção de autores estruturalfuncionalistas.

35. "Eu acho que ele estava solitário, e que ficou muito feliz quando eu o convidei..." (Rose apud Hunter, 1987: xxix).
Cox permanece na Wiley College até 1944, quando passa então a lecionar no Tuskegee Institute e, após 1949, na Lincoln University, Missouri, por 21 anos. Durante esse período, não só trabalhou em isolamento como viveu em isolamento. Nunca se casou e viveu os 21 anos em um apartamento de dois cômodos no dormitório estudantil da universidade (McAuley, 2004: 61). Barbara Celarent coloca como hipótese que esse aspecto - a solidão -, motiva, de alguma forma, a crítica que Cox fez à Escola de Castas.

É possível se perguntar, de fato, se Cox se sentiu tão isolado ao ponto de pensar que não teria nada a perder. Talvez ele já estivesse no caminho do ressentimento que produziu sua denúncia vitriólica nos anos 60 do mais famoso sociólogo negro de sua era [Frazier] (Celarent, 2011: 1667).

Após se aposentar da Lincoln University, Cox cogita voltar a Trinidad, mas o que define como "problemas" - provavelmente sua deficiência - o fazem mudar de ideia. Acaba convidado a lecionar na Wayne University pelo chefe do Departamento de Sociologia da instituição, Alvin Rose, que achava que Cox estivesse "muito solitário"35. Morre em 1974, provavelmente sem nenhuma pista dos caminhos que as leituras futuras de sua obra seguiriam.

\section{Conclusão:}

\section{a Escola de Chicago revisitada}

A atenção que demos à trajetória de Oliver C. Cox possibilita ainda outro deslocamento: o de repensar a história da sociologia como disciplina. A particularidade do peso da exclusão na trajetória do autor o aproxima de maneira significativa de outro intelectual negro que em suas práticas intelectuais desafiou o establishment sociológico norte-americano: W. E. B. Du Bois. Aldon Morris (2015) examina em The scholar denied os mecanismos sociais que obliteraram o projeto da Escola de Sociologia fundada por esse autor em Atlanta. De acordo com Morris, houve um esforço ativo por parte de membros da Escola de Chicago, em particular Robert Park, em minar o projeto, e um esforço posterior igualmente ativo em apagá-lo da história e apresentar Chicago como o berço da sociologia científica na América. A investigação de Morris tenta restaurar o estatuto de clássico a um autor que, por motivos de raça e império, foi negado o acesso a redes intelectuais de elite.

Um esforço análogo é possível com Oliver Cox, pois uma análise sobre sua obra também nos diz muito sobre a sociologia que se fazia em Chicago. Deegan chama atenção ao fato de que para além do "véu", que discutimos na seção anterior, a Escola de Chicago de Relações Raciais operava uma série de outros fatores hegemônicos. 
Durante sua investigação acerca da Escola de Chicago, a autora encontrou inúmeros relatos de pesquisadores, a maioria brancos, que descreviam as técnicas para permanecer um "insider" dentro do que chamaram de "a máfia de Chicago" (Deegan, 2000: 282). Por medo, a maior parte dos entrevistados não quis se identificar.

\footnotetext{
Essa escola inteira tinha uma história institucional única em termos de poder, visibilidade e controle sobre o conhecimento associado a ela. [...] esse controle às vezes violava a liberdade acadêmica e limitava profundamente a busca por verdade e justiça social, e Cox foi vítima desse processo (Deegan, 2000: 282).
}

A autora demonstra, ainda, que Cox passa a desaparecer das narrativas acerca da história da Escola de Chicago que se sucederam, e nas ocasiões em que é mencionado ou reconhecido, aparece como alguém externo à escola, seja por um viés negativo, como faz Van den Berghe - para criticar o que entende como uma incompreensão acerca do sistema de castas -, ou positivo, como fazem Hunter e Klarlund. "O véu da sociologia e o padrão hegemônico de citações e definições de quem estava dentro ou fora da Escola de Chicago de Relações Raciais, logo, continua" (Deegan, 2000: 283).

Com isso, Deegan deseja restaurar a Cox um lugar nessa narrativa, com o objetivo de trazê-lo da "periferia para o centro da sociologia" (Deegan, 2000: 285). Para isso, recorre a uma noção ampliada da Escola de Chicago de relações raciais, de 1892 a 1960. De fato, é frequente o questionamento sobre a existência efetiva de uma Escola de Chicago (Becker, 1999; Harvey, 1986), principalmente ao se considerar a extrema diversidade interna muitas vezes reconhecida. Não obstante, Deegan opta por identificar algumas unidades nessa diversidade, e sua noção ampliada de Chicago passa a ser segmentada. Nessa vertente, Cox teria uma continuidade com o segmento inicial da Escola de Chicago, a Escola Hull House de Relações Raciais, que apostava na educação e na democracia como "mecanismos significativos para organizar e melhorar a sociedade, especialmente as relações entre americanos negros e brancos" (Deegan, 2008b: 659).

Seja como for, a figura de intelectuais como Cox e seu estudo é revelador de tensões na área das ciências sociais, principalmente aquelas acerca da classificação de perspectivas subalternas. Deborah Thomas, por outro lado, prefere manter o estatuto de Cox como outsider, e o posiciona dentro do

ímpeto desconstrucionista, mais bem representado em C. L. R. James e Eric Williams; um ímpeto que ligaria as Américas em um quadro analítico comum, e que geralmente privilegia uma estrutura materialista de causalidade - ao invés de psicológica ou cultural (Thomas, 2014: 364-365). 
Independente de qual a afiliação exata de Cox e a conveniência dessa classificação, uma atenção ao autor permite enxergar o problema de outro lugar. Neste texto tentamos mostrar a urgência de outras áreas da sociologia incorporarem desenvolvimentos realizados por pesquisas acerca de raça e etnicidade, e isso não por mera adaptação de agenda às demandas políticas do presente, no sentido de que não o fazer significaria a manutenção de marginalizações anteriores. Embora essa seja uma dimensão em si já importante, há uma urgência porque nossa compreensão de temas caros à formação do campo da sociologia fica comprometida - no caso deste texto, a história da disciplina e uma sociologia dos intelectuais. Tentamos mostrar que essa condição particular de intelectuais afro-diaspóricos, a maneira racialmente sobredeterminada de se encontrarem dentro e fora, ao mesmo tempo, das tradições intelectuais nas quais foram formados, permite que questões importantes para a renovação de paradigmas interpretativos da sociologia sejam levantadas.

\section{Referências}

BECKER, H. The Chicago School, so-called. Qualitative Sociology, v. 22, n. 1, 1999.

BERNADINO-COSTA, J. A prece de Frantz Fanon: oh, meu corpo, faça sempre de mim um homem que questiona! Civitas - Revista de Ciências Sociais, v. 16, n. 3, p. 504-521, 2016.

BHAMBRA, G. Sociology and postcolonialism: another "missing" revolution? Sociology, v. 41, n. 5, p. 871-884, 2007.

BLIZZARD JR., S. W. Caste, class, and race: a study in social dynamics. American Sociological Review, v. 13, n. 3, 1948.

BORDA, E. W. B. Prisma de formação caribenha: a produção social de uma consciência oposicional em C. L. R. James e Oliver C. Cox. Dissertação (Mestrado) - Universidade Federal de São Carlos, São Carlos, SP, 2018.

Ecos de Fanon em Florestan Fernandes. Florestan, Ano I, p. 23-32, Maio 2014.

BOWSER, B P. The contribution of blacks to sociological knowledge: a problem of theory and role to 1950. Phylon, V. 42, n. 2, 1981.

BUHLE, P. The artist as revolutionary. New York: Verso, 1988.

CELARENT, B. Caste, class, and race by Oliver Cromwell Cox. American Journal of Sociology. v. 115, n. 5, p. 1664-1669, 2010. 
CHEESEBORO, A. Conflict and continuity: E. Franklin Frazier, Oliver C. Cox and the Chicago School of Sociology. Journal of the Illinois State Historical Society, v. 92, n. 2, "African Americans in Illinois", Summer 1999.

COULON, A. A Escola de Chicago. Campinas, SP: Papirus, 1995.

COX, O C. Caste, class and race: a study in social dynamics. New York: Doubleday and Company, 1948.

CUDJOE, S. C. L. R. James y la tradición intelectual de Trinidad y Tobago, o no se estudia Shakespeare debajo de un árbol de mango. New Left Review, v. 25, 2004.

DAVIS, A. Mystical sociology. The Journal of Negro Education, v. 17, n. 2, Spring 1948.

DAVIS, K.; MOORE, W. Alguns princípios de estratificação. Estrutura de classes e estratificação social. Rio de Janeiro: Zahar, 1969.

DEEGAN, Mary Jo. Chicago School of race relations. In: Encyclopedia of race, ethnicity and society. Los Angeles; London: Sage Publications, 2008a.

Hull House School of race relations. In: Encyclopedia of race, ethnicity and society. Los Angeles; London: Sage Publications, 2008b.

Oliver C. Cox and the Chicago School of race relations, 1882-1960. In: HUNTER, H. The sociology of Oliver C. Cox: new perspectives. Bingley, UK: Emerald Publishing, 2000.

DU BOIS, W. E. B. As almas da gente negra. São Paulo: Lacerda, 1999.

DUMONT, L. Homo hierarchicus: the caste system and its implications. Chicago, IL: The University of Chicago Press, 1980.

EMMETT, R. B. Frank H. Knight, Max Weber, Chicago Economics, and institutionalism. In: . Max Weber studies: Weber and economics, Beiheft 1, 2006.

FANON, F. Pele negra, máscaras brancas. Salvador: Editora UFBA, 2008.

FAUSTINO, D. Frantz Fanon: um revolucionário particularmente negro. São Paulo: Ciclo Contínuo Editorial, 2018.

Por que Fanon, por que agora?: Frantz Fanon e os fanonismos no Brasil. Tese (Doutorado em Sociologia) - Programa de Pós-Graduação em Sociologia, Universidade Federal de São Carlos, São Carlos, SP, 2015.

GILROY, P. O Atlântico Negro. São Paulo: Editora 34, 2012. 
GROSSMAN, J R. Land of Hope: Chicago, black southerners, and the great migration. Chicago, IL: University of Chicago Press, 1989.

GUIMARÃES, A. S. A. A recepção de Fanon no Brasil e a identidade negra. Novos Estudos (Cebrap), v. 81, p. 99-114, Jul. 2008.

HALL, Stuart. The fateful triangle: race, ethnicity, nation. Cambridge, MA; London: Harvard University Press, 2017a.

. Familiar stranger: a life between two islands. Durhan, UK: Duke University Press, 2017b.

Negociando identidades caribeñas. In: Sin garantías: trayectorias y problemáticas en estudios culturales. Popayán, CO: Envión editores, 2010.

Epilogue: through the prism of an intellectual life. In: Culture, politics, race and diaspora. Kingston, JM: Ian Randle Publishers, 2007.

The Windrush issue: Postscript. Soundings, issue 10, p. 188-191, 1998.

HARVEY, Lee. The myths of the Chicago School. Quality and Quantity, v. 20, p. 191217, 1986.

HIER, Sean P. The forgotten architect: Cox, Wallerstein and world-system theory. Race Class, v. 42, 2001.

Structures of orthodoxy and the sociological exclusion of Oliver C. Cox. In: HUNTER, H. The sociology of Oliver C. Cox: new perspectives. Bingley, UK: Emerald Publishing, 2000.

HILL, M. Caste, class, and race: a study in social dynamics. Social Forces, v. 27, n. 2 , Dez. 1948.

HOETNIK, H. Race and color in the Caribbean. In: MINTZ, Sidney W.; PRICE, Sally. Caribbean contours. Baltimore, MD: John Hopkins University Press, 1985.

HUGHES, E. P. The literature of race and culture. Phylon, v. 9, n. 1, 1948.

HUNTER, H. M. The life and career of Oliver C. Cox. In: HUNTER, H.; ABRAHAM, S. Race, class and the world system. New York: Monthly Review Press, 1987.

Oliver C. Cox: a biographical sketch of his life and work. Phylon, v. 44, n. 4. p. 249-261, 1983.

JAMES, C . L. R. The class basis of the race question in the United States. New Politics, n. 60, v. XV-4, Winter 2016. Disponível em: <http://newpol.org/content/class-basis-race-question-united-states> 
. Os jacobinos negros: Toussaint Louverture e a Revolução de São Domingos. São Paulo: Boitempo, 2010.

Beyound a boundary. New York: Pantheon, 1983.

JOHNSON, Y. Oliver C. Cox and the Chicago School of Sociology: Its Influence on His Education, Marginalization, and Contemporary Effect. In: Journal of Black Studies, Vol. 35, No. 1, pp. 99-112. 2004.

KELLEY, R. D. G. But a local phase of a world problem: black history's global vision, 1883-1950. The Journal of American History, v. 86, n. 3, "The nation and beyond: transnational perspectives on United States history: a special issue", Dec. 1999.

KEYS, R. C. Society and sociology: the dynamics of black sociological negation. Phylon, v. 39, n. 1, 1978.

LAMMING, G. The pleasures of exile. Ann Arbor, MI: Michigan University Press, 1992.

LASLETT, B. Biography as historical sociology: the case of William Fielding Ogburn. Theory and Society, v. 20, n. 4, Ago. 1991.

MARTIN, E. P. The sociology of Oliver C. Cox: a systematic inquiry. Dissertação (Mestrada de Sociologia) - Atlanta University, Atlanta, GA, 1971.

MATTOS, Pablo. The silent hero: George Padmore, diáspora e pan-africanismo. Tese (Doutorado em História) - Programa de Pós-Graduação em História Social da Cultura, Pontifícia Universidade Católica do Rio de Janeiro, Rio de Janeiro, 2018.

MCAULEY, C. The mind of Oliver Cox. Notre Dame, IN: University of Notre Dame Press, 2004.

MCKEE. J. Sociology and the race problem: the failure of a perspective. Chicago, IL: The University of Illinois Press, 1993.

MONTAÑEZ PICO, Daniel. La teoría del sistema-mundo es negra y caribeña: capitalismo y racismo en el pensamiento crítico de Oliver Cox. Tabula Rasa, n.28, Bogotá, Jan.-Jun. 2018.

MORRIS, A. The scholar denied: W. E. B. Du Bois and the birth of modern sociology. Los Angeles, CA: University of California Press, 2015.

ORTIZ, Renato. Frantz Fanon: um itinerário político e intelectual. ContemporâneaRevista de Sociologia da UFSCar, v. 4, n. 2, p. 425-442, São Carlos,SP, Jul.-Dez 2014. 
PABLITO, Marcello; ALFONSO, Daniel Angyalossy; PARKS, Letícia (Orgs.). A revolução e o negro. São Paulo: Iskra, 2019.

PARSONS, T. O sistema das sociedades modernas. São Paulo: Pioneira, 1974.

PINTO, Simone Rodrigues; BERNARDES, Aristinete. Identidades caribenhas: crioulização em Édouard Glissant. Sociedade e Estado, v. 34, n. 3, p. 637-660, 2019.

PONTES, H. Círculo de intelectuais e experiência social. Revista Brasileira de Ciências Sociais, v. 12, n. 34, 1997.

REDDOCK, Rhoda. Radical Caribbean social thought: race, class identity and the postcolonial nation. Current Sociology, v. 62, n. 4, p. 493-511, Jul. 2014.

SAPIRO, G. Le champ est-il national?: la théorie de la différenciation sociale au prisme de l'histoire globale. Actes de la Recherche en Sciences Sociales, n. 200, 2013.

SEGAL, D. Race and "colour" in pre-independence Trinidad and Tobago. In: Trinidad Ethnicity. London: The Macmilan Press, 1993.

SEGATO, R. Raça é signo. Série Antropologia. Brasília: UnB, 2005.

STANFIELD, J. The Cracked back door: foundations and black social scientists between the World Wars. The American Sociologist, v. 17, n. 4, 1982.

STEPHENS, M. A. Black transnationalism and the politics of national identity: West Indian intellectuals in Harlem in the age of War and Revolution. American Quarterly, v. 50, n. 3, 1998.

SWEEZY, P. Foreword. In: COX, Oliver C. Race, class and the world system. New York: Monthly Review Press, 1987.

THOMAS, Deborah A. Cox's America: caste, race, and the problem of culture. Canadian Journal of Latin American and Caribbean Studies, v. 39, n. 3, p. 364-381, 2014.

WALLERSTEIN, I. Oliver C. Cox as world system analyst. In: HUNTER, H. The sociology of Oliver C. Cox: new perspectives. Bingley, UK: Emerald Publishing, 2000.

WINSTON, M. R. Through the back door: academic racism and the negro scholar in historical perspective. Dædalus, v. 100, v. 3, 1971.

WYNTER, S. Beyond the categories of the master conception: the counterdoctrine of Jamesian poiesis. In: JAMES, C. L. R. Caribbean. Durhan, UK: Duke University Press, 1992. 
YELVINGTON, Kevin. Introduction. In: Trinidad Ethnicity. London: The Macmilan Press, 1993.

YOUNG JR., Alford A.; DESKINS JR., Donald R. Early traditions of African-american sociological thought. Annual Review of Sociology, v. 27, 2001.

(c) (1) (9) 
